\title{
PERBEDAAN ANGKA KAPANG KHAMIR PADA JAMU BERAS KENCUR GENDONG DI PASAR TRADISIONAL DENGAN JAMU BERAS KENCUR KEMASAN DI DEPOT JAMU KOTA BANDAR LAMPUNG
}

\author{
Febri Yanti Santika', Marhamah², Wimba Widagdho Dinutanayo²
}

\author{
${ }^{1}$ Program Studi Teknologi Laboratorium Medis Program Sarjana Terapan \\ ${ }^{2}$ Dosen Jurusan Analis Kesehatan Poltekkes Tanjungkarang
}

[Email korespondensi : febrysantika@gmail.com]

\begin{abstract}
The Differences Betwwen Numbers Of Yeast Mold On Kencur Rice Herbal Medicine In Traditional Market And Packaged Kencur Rice Herbal Medicine In Bandar Lampung Herbal Medicine Depot. Jamu is a traditional medicine that contains several plant ingredients to make herbal medicine. Kencur rice herbal medicine is one of the herbs sold by herbal traders. Large number of mushrooms, indicating the quality of herbal medicine produced. Fungi that produce toxic substances or toxins can poison the body's organs and even cause cancer. The purpose of this study is to find out the differences in the number of yeast molds in the kencur kendur rice herbal medicine in traditional markets and the packaged kencur rice herbal medicine in Bandar Lampung herbal medicine depot. This type of quantitative descriptive research with causative comparative design. Data analysis using Independent $T$ test. The results of the study of 10 kencur rice herbal medicine namely, 5 kencur kencur rice herbal medicine in traditional markets and 5 packaged kencur rice herbal medicine in the herbal medicine depot. The results of mold number 5 yeast herbal medicine for rice kencur carrying $2.55 \times 102$ to $95,5 \times$ 103 colonies / $\mathrm{mL}$ showed that the sample did not meet the requirements, that is, sample C $95.5 \times 103$ colonies / $\mathrm{mL}$ and sample D $7.1 \times 103$ colonies / mL with the results of the percentage meeting the $60 \%$ requirement while not meeting the $40 \%$ requirement. The yield of yeast mold numbers 5 packaged rice kencur rice $4.5 \mathrm{x}$ 102 to $6.3 \times 102$ colonies / g with a percentage of $100 \%$. The analysis results obtained $p$ value 0.311 there was no significant difference in the herbal medicine for kencur rice carrying the packaging because $(p>0.05)$.
\end{abstract}

Keywords : Yeast Figures, Kencur Gendong Rice Herbal Medicine, Kencur Rice Packing.

\begin{abstract}
Abstrak: Perbedaan Angka Kapang Khamir Pada Jamu Beras Kencur Gendong Di Pasar Tradisional Dengan Jamu Beras Kencur Kemasan Di Depot Jamu Kota Bandar Lampung. Jamu adalah obat tradisional yang berisi beberapa bahan tanaman menjadi penyusun jamu. Jamu beras kencur merupakan salah satu jamu yang dijual oleh pedagang jamu. Jumlah jamur yang besar, menunjukkan mutu jamu yang dihasilkan. Jamur yang menghasilkan zat racun atau toksin dapat meracuni organ tubuh bahkan mengakibatkan kanker. Tujuan penelitian ini mengetahui perbedaan angka kapang khamir pada jamu beras kencur gendong di pasar tradisional dengan jamu beras kencur kemasan di depot jamu Kota Bandar Lampung. Jenis penelitian deskriptif kuantitatif dengan desain kompratif kausual. Analisis data menggunakan uji T Independent. Hasil penelitian dari 10 jamu beras kencur yaitu, 5 jamu beras kencur gendong di pasar tradisional dan 5 jamu beras kencur kemasan di depot jamu. Hasil angka kapang khamir 5 jamu beras kencur gendong 2,55 × $10^{2}$ sampai $95,5 \times 10^{3}$ koloni/mL didapatkan sampel tidak memenuhi syarat yaitu, sampel C 95,5 x $10^{3} \mathrm{koloni} / \mathrm{mL}$ dan sampel D $7,1 \times 10^{3} \mathrm{koloni} / \mathrm{mL}$ dengan hasil persentase memenuhi syarat $60 \%$ sedangkan tidak memenuhi syarat $40 \%$. Hasil angka kapang khamir 5 jamu beras kencur kemasan $4,5 \times 10^{2}$ sampai $6,3 \times 10^{2} \mathrm{koloni} / \mathrm{g}$ dengan hasil persentase $100 \%$. Hasil analisis diperoleh $p$ value 0,311 tidak ada perbedaan signifikan pada jamu beras kencur gendong dengan kemasan karena $(p>0,05)$.
\end{abstract}

Kata Kunci : Angka Kapang Khamir, Jamu Beras Kencur Gendong, Jamu Beras Kencur Kemasan. 


\section{PENDAHULUAN}

Jamu adalah obat tradisional yang berisi beberapa bahan tanaman yang menjadi penyusun jamu tersebut. Jamu disajikan dalam bentuk seduhan, pil, atau cairan yang mengacu pada resep peninggalan leluhur. Satu jenis jamu disusun dari berbagai tanaman obat yang jumlahnya 5-10 macam, bahkan bisa lebih (Suharmiati \& Handayani, 2006). Biasanya jamu dijual di pasar atau dijual dengan berkeliling dalam bentuk produk minuman yang dibuat dari bahan segar selain itu dapat pula dijual di kios-kios baik dalam bentuk minuman maupun dalam bentuk jamu bubuk atau pil. Varian jamu yang umum dijual oleh para pedagang jamu diantaranya jamu cabe puyang, jamu godogan, kunyit asam, dan beras kencur (Winarno \& Agustinah, 2005).

Jamu beras kencur merupakan salah satu jamu yang dijual oleh pedagang jamu. Jamu beras kencur merupakan ramuan dari campuran tepung beras dan kencur yang berkhasiat sebagai obat pegal-pegal, batuk, gatal-gatal pada tenggorokan, perut kembung, rasa mual, masuk angin dan bahkan penambah nafsu makan (Winarno \& Agustinah, 2005).

Jamu beras kencur banyak dikonsumsi dari kalangan anak-anak hingga orang dewasa karena rasanya yang tidak pahit. Hasil penelitian Pramudya (2008), tentang uji angka kapang/khamir dalam jamu gendong beras kencur yang beredar di tiga pasar di Kotamadya Yogyakarta, terdapat 5 sampel jamu gendong beras kencur serta angka kapang khamir tidak memenuhi syarat MA PPOMN 2006 yaitu $\leq 10^{3}$ koloni $/ \mathrm{ml}$. Terdapat angka kapang khamir sampel $1=36 \mathrm{x}$ $10^{3} \mathrm{koloni} / \mathrm{ml}$, sampel $2=80 \times 10^{3}$ koloni $/ \mathrm{ml}$, sampel $3=18 \times 10^{5}$ koloni/ml, sampel $4=12 \times 10^{4}$ koloni $/ \mathrm{ml}$, sampel $5=44 \times 10^{5}$ koloni/ml. Sedangkan hasil penelitian Dewi (2016), tentang uji angka kapang-khamir dan identifikasi Salmonella spp pada jamu beras kencur yang dijual di Pasar Sambilegi Maguwoharjo Depok Sleman Yogyakarta, bahwa terdapat 3 hasil pemeriksaan jamu beras kencur tidak memenuhi syarat BPOM RI Nomor 12 Tahun $2014 \leq 10^{3}$ koloni/ml yakni, 6,9 x $10^{5} \mathrm{koloni} / \mathrm{ml}, 2,9 \times 10^{6} \mathrm{koloni} / \mathrm{ml}$ dan $2,2 \times 10^{6} \mathrm{koloni} / \mathrm{ml}$, serta tidak terdapat cemaran bakteri patogen Salmonella spp. Dilihat dari hasil penelitian sebelumnya bahwa jamu beras kencur yang telah diproduksi dapat terkontaminan kapang khamir. $\mathrm{Hal}$ ini dianggap sangat perlu dilakukan pemeriksaan angka kapang khamir pada jamu beras kencur, karena bahan baku dan cara pengolahan bahan baku yang tidak baik menyebabkan terkontaminasi oleh kapang khamir.

Proses pembuatan jamu beras kencur gendong masih dilakukan dengan cara sederhana dan tidak mengalami pemanasan. Peralatan yang digunakan untuk proses pembuatan tidak melewati tahap sterilisasi. Pembuatannya menggunakan tangan peracik jamu itu sendiri, mulai dari proses penghalusan bahan-bahan jamu beras kencur hingga menjadi air perasan yang kemudian disaring. Hal ini memungkinkan terjadinya kontaminasi oleh kapang khamir (Winarno \& Agustinah, 2005). Bentuk kapang juga terjadi pada kondisi jamur sebagai saprofit, misalnya di dalam tanah. Kapang yang terdapat didalam tanah ialah Aspergillus flavus. Bahan jamu beras kencur menggunakan rimpang kencur. Rimpang kencur tumbuh di dalam tanah. Tercemarnya jamu oleh kapang Aspergillus flavus dapat melalui bahan baku yang digunakan dalam pembuatan jamu beras kencur. Kencur yang tidak dicuci bersih kemungkinan besar akan terkontaminasi oleh kapang Aspergillus flavus (Pratiwi, 2008).

Hasil observasi cara penyajian jamu gendong yakni, secara langsung oleh penjual ke pembeli dengan cara menuangkan jamu dari botol ke gelas. Penyajian yang dilakukan penjual jamu gendong masih dibilang tidak mengutamakan higenitas, gelas yang dipakai penjual jamu gendong biasanya dicuci diember kecil tanpa menggunakan sabun dan tidak dikeringkan terlebih dahulu menggunakan lap bersih. Khamir yang bersifat patogen untuk manusia yaitu Candida albicans, Sachromyceses, Cryptococcus neoformans khamir tersebut dapat diisolasi dari air sehingga memungkinkan terjadi kontaminasi oleh khamir yang ada di 
air Candida albicans, Sachromyceses, Cryptococcus neoformans (Gandjar dkk, 2006).

Hasil penelitian Asna dkk, (2016) tentang, isolasi dan identifikasi kapang kontaminan pada jamu serbuk pegal linu dan galian singset yang dijual di Kota Pare Kabupaten Kediri terdapat 8 jenis kapang, kapang kontaminan paling dominan pada jamu serbuk yaitu Aspergillus niger. Dilihat dari hasil penelitian sebelumnya bahwa jamu beras kencur yang telah diproduksi memungkinkan terjadi kontaminan kapang khamir.

Proses pembuatan jamu kemasan diolah oleh pabrik melalui proses sterilisasi terlebih dahulu. Pengolahan terhadap bahan baku jamu beras kencur, kencur harus mengalami proses pengeringan terlebih dahulu. Pengeringan dapat menggunakan sinar matahari, waktu pengeringan bahan baku dapat tercemar karena di udara terbuka memungkinkan terjadi kontaminan kapang khamir (Wasito, 2011). Kapang yang dapat tumbuh pada bahan rempah-rempah pada saat pengeringan ialah Aspergillus flavus, $A$. sydowi, A. tamarii, $A$. versicolor, Emericella nidulans, Eurotium chevalieri, Paecilomyces variotii, dan Penicillium citrinum (Gandjar dkk, 2006). Cara penyajian jamu kemasan serbuk instan yaitu, penjual membuka jamu kemasan lalu dilarutkan dengan air panas langsung disajikan kepada pembeli (BPOM, 2014).

Jumlah jamur yang besar, menunjukkan mutu jamu yang dihasilkan. Beberapa jamur tertentu ada yang menghasilkan zat racun atau toksin seperti pada jamur Asprgillus flavus dapat menghasilkan aflatoksin yang dapat meracuni organ tubuh bahkan mengakibatkan kanker. Jamu dipersyaratkan angka kapang khamir jika terdapat aflatoksin maka tidak boleh lebih dari 30 bpj (bagian per juta) dari sedian tersebut (Wasito, 2011).

Mikotoksikosis yaitu keracunan mengkonsumsi makanan yang tercemar oleh mikotoksin yang mengandung aflatoksin menyebabkan kanker hati (Syarief dkk, 2003). Hal ini dapat terjadi karena kurangnya kebersihan dari penjual jamunya sehingga memberikan efek keracunan.
Efek samping dari mengkonsumsi jamu seperti keracunan yang ditandai dengan muntah-muntah, diare, pusing, perut terasa panas (Vialain, 2012). Kanker hati yang disebabkan oleh toksin jamur diderita 500.000 orang tiap tahunnya di dunia. Tahun 2004 di Kenya terdapat 400 kasus kematian akibat keracunan toksin yang dihasilkan jamur pada makanan. Di Indonesia diperkirakan jumlah kematian karena kanker hati yang disebabkan toksin jamur lebih dari 20.000 orang pertahun (Yenny, 2006).

Pasar tradisional merupakan salah satu tempat penjualan jamu gendong yang menjuali jamunya pada masyarakat. Hasil observasi di Pasar Tradisional Kota Bandar Lampung didapatkan 12 Pasar Tradisonal di Kota Bandar Lampung yang mewakili dari 11 Kecamatan, yaitu Kecamatan Bumi Waras, Kecamatan Panjang, Kecamatan Sukarame, Kecamatan Tanjung Karang Timur, Kecamatan Tanjung Karang Pusat, Kecamatan Kemiling, Kecamatan Way Halim, Kecamatan Tanjung Senang, Kecamatan Labuhan Ratu, Kecamatan Kedaton, dan Kecamatan Rajabasa. Terdapat 14 penjual jamu gendong dari 12 pasar tradisional dan 11 kecamatan Kota Bandar Lampung. Setiap pasar tradisional hanya ada 1-2 penjual jamu gendong. Jamu beras kencur biasanya dijual oleh tukang jamu gendong, pembeli membeli jamu gendong biasanya per gelas dimana 1 botol berisi 10 gelas. Penjual jamu gendong dapat menjual seluruh jamunya 30-50 gelas per harinya (Badan Pusat Statistik, 2014).

Depot jamu merupakan salah satu tempat menjual jamu yang berbagai macam jamu yang diolah menjadi bentuk serbuk jamu, pil, jamu racikan, dan lain-lain. Hasil observasi jamu serbuk kemasan beras kencur di Depot Jamu Kota Bandar Lampung didapatkan 5 penjual jamu kemasan beras kencur di 4 kecamatan Kota Bandar Lampung yaitu, Kecamatan Way Halim Permai, Kecamatan Tanjung senang, Kecamatan Tanjung Karang Timur, dan Depot Kecamatan Kedaton. Setiap depot jamu hanya menjual 1 jamu serbuk kemasan beras kencur. Depot jamu dikunjungi oleh pembeli 15-25 orang per harinya. 


\section{METODE}

Kajian penelitian ini adalah bidang Mikologi dengan jenis penelitian ini deskriptif kuantitatif dengan desain penelitian kompratif kausual yaitu, perbedaan angka kapang khamir pada jamu beras kencur gendong di pasar tradisional dengan jamu beras kencur kemasan di depot jamu Kota Bandar Lampung. Variabel indepedent adalah jamu beras kencur gendong di pasar tradisional dengan jamu beras kencur kemasan di depot jamu, variabel dependent adalah angka kapang khamir.

Populasi penelitian ini adalah jamu beras kencur gendong di pasar tradisional dengan jamu beras kencur kemasan di depot jamu Kota Bandar Lampung, yang terdiri dari 14 penjual jamu beras kencur gendong di pasar tradisional dengan 5 penjual jamu beras kencur kemasan di depot jamu. Sampel penelitian ini adalah 10 sampel yaitu 5 jamu beras kencur gendong di pasar tradisional dengan 5 jamu beras kencur kemasan di depot jamu Kota Bandar Lampung. Sampel diambil dengan cara simple random sampling pada jamu beras kencur gendong dengan cara undian.

Metode uji yang digunakan dalam penelitian adalah cawan tuang. Prinsip penelitian ini adalahm Pertumbuhan kapang khamir dalam media PDA, setelah diinkubasi pada suhu $25^{\circ} \mathrm{C}$ atau pada suhu kamar selama 5 hari.Tempat penelitian dilakukan di Laboratorium Bakteriologi Jurusan Analis Kesehatan Poltekkes Tanjungkarang pada bulan Maret-April 2020. Persiapan alat dan bahan ialah Alat yang digunakan meliputi autoklaf, oven, cawan petri $(100 \times 15 \mathrm{~mm})$, pipet ukur $1 \mathrm{ml}$ dan 10 $\mathrm{ml}$, lemari inkubator, erlenmeyer, neraca elektrik, gelas ukur, spatula, batang pengaduk, hot plate, vortex, tabung reaksi, kertas kopi/koran, kapas, lampu spirtus, dan mikroskop. Bahan yang digunakan meliputi sampel jamu beras kencur gendong, jamu beras kencur kemasan, media PDA (Potato Dextrose Agar), larutan kloramfenicol, media PDF (Pepton Dilution Fluid), dan aquades. Prosedur pemeriksaan angka kapang khamir ialah Dipipet $25 \mathrm{ml}$ sampel ditambahkan $225 \mathrm{ml}$ larutan pengencer
PDF dan dihomogenkan hingga diperoleh pengenceran $10^{-1}$.

Ditimbang $25 \mathrm{~g}$ sampel, masukkan ke dalam erlenmeyer yang telah berisi $225 \mathrm{ml}$ larutan pengencer PDF lalu di add hingga $250 \mathrm{ml}$ dan dihomogenkan hingga diperoleh pengenceran $10^{-1}$ (BPOM, 2006). Sebanyak 4 buah tabung reaksi disiapkan, masing-masing diisi dengan $9 \mathrm{ml}$ larutan pengencer PDF. Sebanyak $1 \mathrm{ml}$ pengenceran $10^{-1}$ dari hasil homogenisasi pada penyiapan sampel diambil dan dimasukkan ke dalam tabung pertama yang telah diisi $9 \mathrm{ml}$ larutan pengencer PDF hingga diperoleh pengenceran $10^{-2}$ (homogenkan dengan vortex).

Selanjutnya dibuat pengenceran hingga $10^{-4}$ dan kontrol. Dipipet $0,5 \mathrm{ml}$ masing-masing pengenceran $10^{-1}-10^{-4}$ dan kontrol ke dalam cawan petri secara duplo pada setiap pengenceran. Dituangkan media PDA sebanyak \pm 20 $\mathrm{ml}$ ke dalam cawan petri yang sebelumnya telah ditambah dengan 1 ml larutan kloramfenikol dan digoyangkan sehingga campuran tersebut merata. Setelah agar membeku, cawan petri dibalik dan diinkubasikan pada suhu $25^{\circ} \mathrm{C}$ atau pada suhu kamar selama 5 hari. Pengamatan diamati pada hari ke-3 sampai hari ke-5. Koloni kapang khamir dihitung setelah 5 hari, setelah dihitung koloni angka kapang khamir lanjutkan pengolahan data (BPOM, 2006).

Analisis data univariat yaitu menghitung persentase angka kapang khamir pada jamu beras kencur gendong di pasar tradisional dengan jamu beras kencur kemasan di depot jamu. Analisis data bivariat yaitu uji T Independent.

\section{HASIL}

Penelitian tentang perbedaan angka kapang khamir pada jamu beras kencur gendong di pasar tradisional dengan jamu beras kencur kemasan di depot jamu Kota Bandar Lampung dan dilakukan di Laboratorium Bakteriologi Jurusan Analis Kesehatan Poltekkes Tanjungkarang, dengan 10 sampel yaitu 5 jamu beras kencur gendong di pasar tradisional dengan 5 jamu beras kencur kemasan di depot jamu didapatkan hasil sebagai berikut: 
Jumlah angka kapang khamir pada 5 jamu beras kencur gendong di 5 Pasar Tradisional Kota Bandar Lampung dengan hasil angka kapang khamir 2,55 × $10^{2}$ sampai $95,5 \times 10^{3}$ koloni/mL dari 5 jamu beras kencur gendong didapatkan 2 jamu beras kencur gendong tidak memenuhi syarat pada sampel $\mathrm{C} 95,5 \times 10^{3} \mathrm{koloni} / \mathrm{mL}$ dan sampel $D \quad 7,1 \times 10^{3}$ koloni $/ \mathrm{mL}$ dengan hasil persentase angka kapang khamir $60 \%$ memenuhi syarat dan $40 \%$ tidak memenuhi syarat BPOM RI No.12 Tahun 2014, yaitu $\leq 10^{3}$ koloni/mL.

Tabel 1. Jumlah dan Persentase Angka Kapang Khamir pada Jamu Beras Kencur Gendong di Pasar Tradisional Kota Bandar Lampung

\begin{tabular}{lcccccc}
\hline No & $\begin{array}{c}\text { Jamu Beras Kencur } \\
\text { Gendong }\end{array}$ & $\begin{array}{c}\text { Angka Kapang } \\
\text { Khamir (koloni/mL) }\end{array}$ & \multicolumn{2}{c}{ Keterangan } & & $\%$ \\
& & MS & TMS & MS & TM \\
\hline 1 & A & $5,45 \times 10^{2}$ & 1 & 0 & 60 & 40 \\
2 & B & $4,05 \times 10^{2}$ & 1 & 0 & & \\
3 & C & $95,5 \times 10^{3}$ & 0 & 1 & & \\
4 & D & $7,1 \times 10^{3}$ & 0 & 1 & & \\
5 & E & $2,55 \times 10^{2}$ & 1 & 0 & & 40 \\
\hline
\end{tabular}

Keterangan:

MS : Memenuhi syarat BPOM RI No.12 Tahun 2014, yaitu $\leq 10^{3} \mathrm{koloni} / \mathrm{mL}$

TMS : Tidak memenuhi syarat BPOM RI No.12 Tahun 2014, yaitu $\geq 10^{3} \mathrm{koloni} / \mathrm{mL}$

A-E : Kode jamu beras kencur gendong

Tabel 2. Jumlah dan Persentase Angka Kapang Khamir pada Jamu Beras Kencur Kemasan di Depot Jamu Kota Bandar Lampung

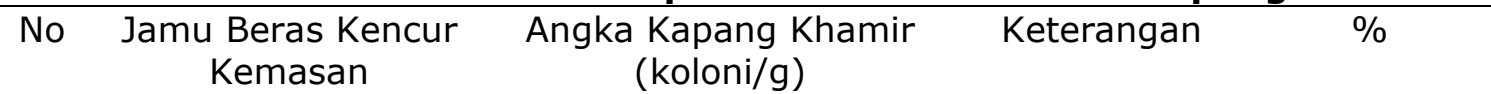

\begin{tabular}{lllllll} 
& & & MS & TMS & MS & TMS \\
\hline 1 & 1 & $5,3 \times 10^{2}$ & 1 & 0 & 100 & 0 \\
2 & 2 & $4,5 \times 10^{2}$ & 1 & 0 & & \\
3 & 3 & $6,3 \times 10^{2}$ & 1 & 0 & & \\
4 & 4 & $4,8 \times 10^{2}$ & 1 & 0 & & \\
5 & 5 & $4,9 \times 10^{2}$ & 1 & 0 & & \\
\hline & Jumlah & & 5 & 0 & 100 & 0 \\
\hline
\end{tabular}

Keterangan:

MS : Memenuhi syarat BPOM RI No.12 Tahun 2014, yaitu $\leq 10^{3} \mathrm{koloni} / \mathrm{g}$

TMS : Tidak memenuhi syarat BPOM RI No.12 Tahun 2014, yaitu $\geq 10^{3}$ koloni/g

1-5 : Kode jamu beras kencur kemasan

Jumlah angka kapang khamir pada 5 jamu beras kencur kemasan di 5 Depot Jamu Kota Bandar Lampung didapatkan hasil angka kapang khamir $4,5 \times 10^{2}$ sampai $6,3 \times 10^{2}$ koloni $/ g$ dengan hasil persentase angka kapang khamir $100 \%$ memenuhi syarat BPOM RI No.12 Tahun 2014, yaitu $\leq 10^{3}$ koloni/g.

Hasil penelitian selanjutnya dianalisis dengan menggunakan uji $\mathrm{T}$ Independent untuk melihat perbedaan rata-rata dari dua kelompok data yaitu, angka kapang khamir jamu beras kencur gendong dengan jamu beras kencur kemasan. Berdasarkan hasil uji $T$ Independent diatas (Tabel 3) didapatkan $p$ value $=0,311$ yang berarti tidak ada perbedaan signifikan antara angka kapang khamir jamu beras kencur gendong dengan jamu beras kencur kemasan karena $p$ value $>0,05$. 
Tabel 3. Uji T Independent Angka Kapang Khamir pada Jamu Beras Kencur

Gendong di Pasar Tradisional dengan Jamu Beras Kencur Kemasan di Depot Jamu Kota Bandar Lampung

\begin{tabular}{|c|c|c|c|c|}
\hline & Jenis Jamu & $\mathrm{N}$ & Mean & $p$ value \\
\hline \multirow{2}{*}{$\begin{array}{c}\text { Angka Kapang } \\
\text { Khamir }\end{array}$} & $\begin{array}{c}\text { Jamu Beras Kencur } \\
\text { Gendong }\end{array}$ & 5 & 20800.00 & 0.311 \\
\hline & $\begin{array}{c}\text { Jamu Beras Kencur } \\
\text { Kemasan }\end{array}$ & 5 & 516.00 & \\
\hline
\end{tabular}

\section{PEMBAHASAN}

Angka kapang khamir pada 5 jamu beras kencur gendong di pasar tradisional didapatkan hasil 2,55 x $10^{2}$ sampai $95,5 \times 10^{3} \mathrm{koloni} / \mathrm{mL}$. Hasil tersebut menyatakan bahwa persentase angka kapang khamir pada jamu beras kencur gendong di pasar tradisional terdapat $60 \%$ memenuhi syarat dan $40 \%$ tidak memenuhi syarat BPOM RI No.12 Tahun 2014, yaitu $\leq$ $10^{3} \mathrm{koloni} / \mathrm{mL}$.

Jumlah jamu beras kencur yang tidak memenuhi syarat ada 2 jamu beras kencur gendong yang didapatkan hasil angka kapang khamir pada kode sampel C 95,5 x $10^{3}$ koloni $/ \mathrm{mL}$ dan $D$ $7,1 \times 10^{3}$ koloni $/ \mathrm{mL}$. Nilai angka kapang khamir melebihi batas yang ditetapkan. Berdasarkan standar Kemenkes (2015), hal ini bisa dipengaruhi oleh cara pembuatan jamu beras kencur dari bahan baku yang digunakan, wadah dan cara penyimpanan, serta penyajian jamu beras kencur gendong.

Berdasarkan observasi pada pedagang jamu gendong kode sampel $C$ dan $D$, pada saat pencucian rimpang kencur dan beras yang merupakan bahan baku utama pembuatan jamu beras kencur, rimpang kencur hanya direndam tetapi tidak dicuci di air mengalir. Menurut Dewi (2016), pada saat pencucian rimpang kencur yang merupakan bahan baku pembuatan jamu beras kencur hanya satu kali dilakukan pencucian. Maka kapang khamir masih menempel pada rimpang kencur apabila pencucian tidak bersih. Berdasarkan standar pembuatan jamu segar yang baik dan benar, mengharuskan pencucian dilakukan dengan mengalirkan air pada rimpang kemudian dilakukan pembersihan dengan cara menyikat bagian yang kotor dan memotong bagian yang sudah membusuk (Kemenkes, 2015).
Salah satu habitat kapang khamir terdapat di dalam tanah dan bahan baku yang digunakan berupa rimpang kencur yang tumbuh di dalam tanah. Oleh karena itu, kapang khamir sangat mudah mencemari bahan baku dan apabila rimpang kencur tidak dicuci dengan bersih, maka kontaminan kapang khamir semakin tinggi pada jamu beras kencur. Kapang khamir menempel pada rimpang kencur dapat menembus sel-sel akar rimpang kencur dan hifa kapang dapat berkumpul ke dalam selubung mengelilingi akar rimpang kencur (Pratiwi, 2008).

Berdasarkan observasi pada pedagang jamu gendong kode sampel $C$ dan $D$, kondisi pasar tempat penjualan jamu gendong kode sampel C terbuka dan kode sampel D tertutup. Kondisi pasar yang terbuka dapat memudahkan kontaminasi kapang khamir karena spora kapang dapat berterbangan di udara kemudian mencemari jamu gendong. Kondisi pasar yang tertutup dalam keadaan gelap atau kurang pencahayaan dan lembab, keadaan seperti ini dapat mempengaruhi pertumbuhan kapang khamir. Penyebaran kapang dapat melalui spora yang berterbangan di udara karena spora kapang yang kecil dan ringan sehingga dapat dengan mudah terbawa oleh angin. Lingkungan yang hangat dan lembab mempercepat pertumbuhan kapang khamir (Pratiwi, 2008).

Selain itu pada pedagang jamu gendong kode sampel $C$ pada saat penyajian jamu gendong secara langsung oleh penjual ke pembeli dengan menghomogenkan jamu setelah itu dituangkan ke dalam plastik dengan menggunakan corong. Corong yang digunakan penjual jamu gendong tidak dicuci dengan bersih, hanya dengan dicelupkan saja ke dalam air 
diember, tanpa menggunakan sabun Berdasarkan standar pembuatan jamu segar yang baik dan benar, aspek kebersihan peralatan jamu gendong dicuci bersih peralatan dengan sabun, lalu dikeringkan terlebih dahulu. Pencucian tidak menggunakan sabun dan tidak dikeringkan terlebih dahulu masih keadaan basah dapat menyebabkan kapang khamir menempel pada peralatan (Kemenkes, 2015). Sedangkan pada pedagang jamu gendong kode sampel D menggunakan wadah botol bekas air mineral tidak sesuai dengan standar kesehatan, botol yang harus digunakan pada jamu gendong yaitu, botol kaca atau botol plastik yang sesuai dengan standar kesehatan, tidak menggunakan botol bekas air mineral atau botol plastik lainnya yang tidak sesuai (Kemenkes, 2015).

Menurut Sholichah (2012), menggunakan botol plastik bekas kemasan air mineral yang digunakan

berkali-kali tanpa diganti. Botol tersebut merupakan botol berkode angka 1 yang direkomendasikan hanya sekali pakai. Pada saat digunakan untuk menampung jamu dapat mempengaruhi mutu akhir dari jamu. Angka kapang khamir pada

jamu beras kencur kemasan 4,5 $510^{2}$ sampai $6,3 \times 10^{2} \mathrm{koloni} / \mathrm{g}$ dengan hasil persentase angka kapang khamir 100\% memenuhi syarat BPOM RI No.12 Tahun 2014, yaitu $\leq 10^{3}$ koloni/g. Angka kapang khamir pada jamu beras kencur kemasan memenuhi syarat karena dipengaruhi proses pembuatan hingga penyimpanan jamu kemasan. Proses pembuatan jamu kemasan yaitu, pencucian bahan baku dibersihkan di air mengalir, setelah itu bahan baku dikeringkan terlebih dahulu untuk mencegah pertumbuhan kapang khamir agar mencapai kadar air 10\%. Peralatan yang digunakan harus bersih dan disterilkan terlebih dahulu. Jamu yang akan dikemas dengan bahan pengemasan yang sesuai dalam wadah tertutup rapat. Dalam penyimpanan jamu kemasan harus disimpan pada suhu kamar, di tempat kering dan terlindung dari sinar matahari (Wasito, 2011).

Berdasarkan observasi, pada pedagang jamu beras kencur kemasan penyimpanan jamu beras kencur dan tidak dikeringkan terlebih dahulu. kemasan disimpan pada suhu kamar matahari. Dalam penyimpanan jamu kemasan disimpan pada suhu kamar $15^{\circ} \mathrm{C}$ sampai $30^{\circ} \mathrm{C}$ serta disimpan di tempat kering adalah yang terhindar dari kelembaban, untuk mencegah $25^{\circ} \mathrm{C}$ sampai $30^{\circ} \mathrm{C}$, disimpan di tempat kering dan terlindungi dari sinar pertumbuhan kapang khamir dari luar dan terjadi peruraian (Wasito, 2011).

Hasil analisis didapati bahwa tidak ada perbedaan yang signifikan antara angka kapang khamir jamu beras kencur gendong dengan jamu beras kencur kemasan. Koloni kapang khamir diidentifikasi secara makrokopis sama antara jamu beras kencur gendong dengan jamu beras kencur kemasan. Namun, jumlah koloni angka kapang khamir pada 3 sampel jamu beras kencur gendong dan 5 jamu beras kencur kemasan memenuhi syarat sedangkan 2 sampel jamu beras kencur gendong tidak memenuhi syarat.

\section{KESIMPULAN}

Kesimpulan dari penelitian ini adalah sebagai berikut:

1. Jumlah angka kapang khamir pada 5 jamu beras kencur gendong di 5 Pasar Tradisional Kota Bandar Lampung dengan hasil angka kapang khamir $2,55 \times 10^{2}$ sampai $95,5 \times 10^{3}$ koloni $/ \mathrm{mL}$. Jumlah angka kapang khamir pada 5 jamu beras kencur kemasan di 5 Depot Jamu Kota Bandar Lampung didapatkan hasil angka kapang khamir 4,5 $\times 10^{2}$ sampai $6,3 \times 10^{2}$ koloni/g.

2. Persentase jamu beras kencur gendong di pasar tradisional yang memenuhi syarat angka kapang khamir $60 \%$ dan tidak memenuhi syarat $40 \%$ dengan syarat berdasarkan BPOM RI No.12 Tahun 2014 yaitu, $\leq 10^{3}$ koloni $/ \mathrm{mL}$. Persentase jamu beras kencur kemasan di depot jamu yang memenuhi syarat angka kapang khamir $100 \%$ dengan syarat berdasarkan BPOM RI No.12 Tahun 2014 yaitu, $\leq 10^{3}$ koloni/g. Angka kapang khamir pada jamu beras kencur gendong dengan jamu beras kencur kemasan 
menunjukkan tidak ada perbedaan signifikan karena $p$ value $>0,05$.

\section{SARAN}

Saran penelitian ini adalah perlu dilakukan pembinaan dan pemberian edukasi terhadap produsen jamu gendong yang tidak memenuhi syarat oleh pihak yang berwenang, terkait higenitas penjual jamu, sehingga dapat mengurangi angka kapang khamir pada jamu gendong. Berdasarkan hasil penelitian yang didapat, jika akan dilakukan penelitian lebih lanjut dapat melakukan penelitian angka kapang khamir dengan penambahan sampel jamu gendong dan identifikasi mikrokopis.

\section{DAFTAR PUSTAKA}

Asna, P., M., A., Mastika, L., M., K., Hastuti, U., S. (2016). Isolasi dan Identifikasi Kapang Kontaminan pada Jamu Serbuk yang dijual di Kota Pare Kabupaten Kediri. Jurnal Biologi: 91-100.

Badan Pengawasan Obat dan Makanan RI. (2006). Metode Analisis PPOM, MPPOMN Nomor 97/mik/00, Uji Angka Kapang Khamir dalam Obat Tradisional. Jakarta: BPOM.

Badan Pengawasan Obat dan Makanan RI. (2014). Peraturan Kepala Badan Pengawasan Obat dan Makanan RI Nomor: 12 Tahun 2014 Tentang Persyaratan Mutu Obat Tradisional. Jakarta: BPOM.

Badan Pusat Statistik Kota Bandar Lampung. (2014). Daftar Nama Pasar Tradisional Kota Bandar Lampung.

https://bandarlampungkota.bps.go.id/s tatictable/2016/01/20/96/daftarnama- pasar-tradisionalmenurut-lokasi-di-kota-bandarlampung-tahun-2014.html [Diakses 14 Januari 2020].

Dewi, (2016). Uji Angka KapangKhamir dan Identifikasi Salmonella spp pada Jamu Beras Kencur yang dijual di Pasar Sambilegi Maguwoharjo Depok Sleman Yogyakarta. [Skripsi]. Yogyakarta:Fakultas Farmasi Universitas Sanata Dharma.
Gandjar, R., Wellyzar, S., Ariyanti, O. (2006). Mikologi Dasar dan Terapan, Edisi 1 Jakarta: Yayasan Pustaka Obor Indonesia.

Kementrian Kesehatan RI. (2015). Pembuatan Jamu Segar yang Baik dan Benar. Jakarta: Kementrian Kesehatan RI.

Pramudya. (2008). Uji Kapang/Khamir dalam Jamu Gendong Beras Kencur yang beredar di Tiga Pasar di Kotamadya Yogyakarta. [Skripsi]. Yogyakarta: Fakultas Farmasi Universitas Sanata Dharma.

Pratiwi, S. T. (2008). Mikrobiologi Farmasi. Jakarta: Erlangga Medical Series.

Sholichah, V. (2012). Kualitas Mikrobiologi Jamu Gendong Jenis Kunir Asem yang Diproduksi di Kelurahan Merbung Kecamatan Klaten Selatan Kabupaten Klaten. Jurnal Kesehatan Masyarakat: 504-523.

Suharmiati \& Handayani. L. (2006). Cara Benar Meracik Obat Tradisional. Jakarta: PT Agromedia Pustaka.

Syarief, R., Ega, L., Nurwitri, C., C. (2003). Mikotoksin Bahan Pangan. Bogor: IPB Press.

Vialin, G. (2012). Pengalaman Keluarga Mengkonsumsi Jamu Dalam Perspektif Sehat Sakit di Desa Jaten Kecamatan Juwiring. [Skripsi]. Surakarta: Universitas Muhammadiyah Surakata.

Wasito, H. (2011). Obat Tradisional Kekayaan Indonesia, Edisi 1. Yogyakarta: Graha Ilmu.

Winarno, F., G. \& Agustinah, W. (2005). Herba dan Rempah Aplikasinya dalam Hidangan, Cetakan 1, Bogor: M-Brio Press.

Yenny. (2006). Aflatoksin dan aflatoksikosis pada manusia. Jakarta.

http://www.univmed.org/wpconte nt/uploads/2012/04/yenni1.pdf [Diakses 7 Oktober 2019]. 